\title{
Orthognathic Surgery: Pretreatment Information and Patient Satisfaction
}

\author{
Lateefa AlKharafi $^{a}$ Dalal AlHajery ${ }^{\mathrm{a}}$ Lars Andersson $^{\mathrm{b}}$ \\ a Department of Dentistry, Ministry of Health, and b Department of Surgical Sciences, Faculty of Dentistry, \\ Health Sciences Center, Kuwait University, Kuwait City, Kuwait
}

\section{Key Words}

Orthognathic surgery · Adverse effects · Surgical risks .

Pretreatment information - Patient satisfaction

\begin{abstract}
Objectives: This study sought to (1) analyze the demographic profile of patients who completed combined orthodontic and surgical treatments at the Kuwait Ministry of Health dental clinics, (2) evaluate the source, type, amount and timing of preoperative patient information, (3) determine posttreatment patient satisfaction and (4) examine whether patient satisfaction is associated with preoperative information. Subjects and Methods: Of the 145 patients who completed combined orthodontic and surgical treatments at least 6 months prior to the initiation of this study, 74 agreed to be interviewed by telephone by means of a structured survey including questions covering the study's objectives. Results: The mean age of participants was 21.1 years; 52 (70.3\%) were female and 22 (29.7\%) were male. Of these 74 patients, 70 (94\%) did not regret their decision to undergo orthognathic surgery and $62(83.8 \%)$ would repeat the same treatment if it was needed. The majority of the respondents reported that the importance of treatment compliance had been explained very well prior to surgery, but that information about the associated functional and social problems was lacking. The orthodontist was the most prominent source of information
\end{abstract}

before treatment began. As the presurgical orthodontic treatment phase progressed, the roles of the surgeon and orthodontist became more evenly distributed. Conclusion: The patients who underwent orthognathic surgery were satisfied and generally well informed. However, information regarding surgical risks and functional discomforts was not adequate. Participants were more likely to be satisfied when they were provided with more information about discomfort and surgical risks.

ㄷ) 2014 S. Karger AG, Basel

\section{Introduction}

Several studies have shown that a high quality and quantity of information prior to treatment is needed to achieve a high level of satisfaction among patients seeking combined orthodontic and surgical treatments [1-3]. Ostler and Kiyak [1] indicated the importance of successful patient-practitioner communication and sufficient preoperative knowledge regarding surgical complications and outcomes. Bailey et al. [2] showed that including patients in the decision-making process increases their awareness and acceptance of the final results. Olson and Laskin [3] showed that dissatisfaction is more related to the quality of the information provided to the patient than the actual quality of the surgical outcome.

Dr. Lateefa AlKharafi

Block 5, Al-Tabari Street, House 9

12113 Al-Shamiyah

Kuwait City 76152 (Kuwait)

E-Mail lateefa_k@yahoo.com
This is an Open A Creative Commons Attribution-NonCommercial 3.0 Unported license (CC BY-NC) (www.karger.com/OA-license), applicable to the online version of the article only. Distribution permitted for non-commercial purposes only. 
Several studies $[4,5]$ have attempted to measure the relationship between the information provided about the side effects of actual surgery and posttreatment satisfaction. The following areas were identified: the most common cause of dissatisfaction was attributed to an insufficient amount of information concerning jaw fixation, the lack of knowledge about the areas subjected to postoperative nerve injury and inadequate explanation of the postoperative diet, swelling, pain and scarring [4]. Rittersma et al. [5] reported other reasons for dissatisfaction with the final outcome to include the lack of information on general anesthesia, the postoperative diet, weight loss, absence from work, loss of tooth sensitivity, possible damage to the dentition, swelling and pain.

The number of patients undergoing different types of orthognathic surgery in Kuwait is increasing, so the need exists for an objective evaluation of patient preparation prior to surgery. The relationship between the information provided to patients before surgery and patient satisfaction with the final outcome has not been evaluated in Kuwait. This study aimed to (1) analyze the demographic profiles of patients treated with combined orthodontic and orthognathic surgeries at the Kuwait Ministry of Health $(\mathrm{MoH})$ dental clinics, (2) evaluate the source, type, amount and timing of preoperative patient information, (3) determine posttreatment patient satisfaction and (4) examine whether patient satisfaction was associated with preoperative information.

\section{Materials and Methods}

Prior to the initiation of the study, the $\mathrm{MoH}$ gave permission to collect data, while ethical approval was given by the Faculty of Dentistry Research Committee.

\section{Participants}

The Orthodontic Unit heads of the various specialist dental centers were approached, and they agreed to provide lists with the names and telephone numbers of all their patients who had undergone combined orthodontic and surgical malocclusion corrections. A total of 204 patients were identified at four specialist dental centers (Al-Amiri, Al-Farwaniya, Al-Adan and Bnaid Al-Gar). Fifty-seven of them were excluded from the list due to the presence of a congenital deformity, history of facial trauma or removal of an appliance $<6$ months previously. Of the remaining 147 patients, 74 agreed to participate in the study via a telephone interview. The interviews were conducted between 6 months and 10 years after appliance removal. Of the consenting patients, 66 had undergone surgery at three different major surgical centers in $\mathrm{Ku}$ wait (Al-Babtain, Al-Amiri and Al-Adan), with 4 being operated on in other hospitals. Only 4 of the surgeries had been performed abroad.

Orthognathic Surgery in Kuwait

\section{Data Collection}

Information regarding gender, age at the time of surgery and appliance removal was collected from the patients' confidential records. The remaining data were collected via individual telephone interviews using a structured questionnaire. The questionnaire included questions on socioeconomic status and level of education as well as where the surgery and orthodontic treatment had been conducted. Other questions covered the type of surgery, patients' motivation, the source and timing of received information, details that had been provided concerning possible risks and discomforts, possible social and functional problems during the recovery period after orthognathic surgery and the importance of self-compliance after surgery. Questions regarding satisfaction with the final outcome were also included. The questionnaire was pilot-tested on a sample of 3 patients who had completed combined orthodontic and surgical treatments provided by the academic staff at the Faculty of Dentistry. Improvements were then made in order to enhance patients' understanding of the words and terms used. Three orthodontists and two surgeons were consulted as to whether all relevant areas had been covered. Questions regarding smoking cessation and the use of elastics were added. The questionnaire addressed patient demographics, the type and timing of receiving general patient information, specific information concerning the risk of adverse effects, the need for patient compliance and patient satisfaction with the final outcome. The interviewers recorded the answers and treated the data confidentially. Each questionnaire received an identification code and the key connecting this code with a patient's name was kept in a locked file available only to the investigators.

\section{Procedure}

The interviewers were the two main investigators (Lateefa AlKharafi and Dalal AlHajery) who had designed the questionnaire and were conducting the study. Patients were called using the telephone numbers recorded on their charts. Three attempts were made to contact each participant. Thorough explanation of the study and its objectives was provided to those reached. Depending on the participant's preferred language, the Arabic or English version of the questionnaire was read over the phone to the patients and their responses were recorded. Each interview took 15-20 min to complete.

\section{Data Analyses}

The data were entered onto an Excel spreadsheet and analyzed using the Statistical Package for Social Sciences (SPSS) version 16.0. The time periods were rounded to the nearest quarter of a year prior to entry. For each patient, the scores in each of the four categories related to general information, specific information concerning surgical risks, information with regard to social and functional problems and information concerning the importance of patient compliance; these were aggregated into one score. Similar aggregations were made for the scores related to actual versus expected outcomes and general satisfaction. If two thirds or more of the responses in any category were recorded as 'very satisfied' and one third or fewer responses were recorded as 'fairly satisfied', then the aggregated score was categorized as 'very satisfied'. Similarly, if two thirds or more of the responses in any category were recorded as 'unsatisfied' and one third or less was recorded as 'fairly satisfied', then the score was aggregated as 'unsatisfied'. The scores of the remaining patients were categorized as 'fairly satis- 
Table 1. Responses to questions regarding the general information received

\begin{tabular}{|c|c|c|c|c|}
\hline & $\begin{array}{l}\text { Cannot recall, } \\
\mathrm{n}(\%)\end{array}$ & $\begin{array}{l}\text { No, } \\
\text { n (\%) }\end{array}$ & $\begin{array}{l}\text { Fairly well, } \\
\text { n (\%) }\end{array}$ & $\begin{array}{l}\text { Very well, } \\
\text { n (\%) }\end{array}$ \\
\hline Need for orthodontics before and after surgery & - & $12(16.2)$ & $14(18.9)$ & $48(64.9)$ \\
\hline Possible surgical risks and postoperative discomfort & $1(1.4)$ & $19(25.7)$ & $17(23)$ & $37(50)$ \\
\hline Possible surgical, orthodontic or both types of relapse & $5(6.8)$ & $47(63.5)$ & $7(9.5)$ & $15(20.3)$ \\
\hline Possible long-term iatrogenic surgery effects & $2(2.7)$ & $32(43.2)$ & $6(8.1)$ & $34(45.9)$ \\
\hline
\end{tabular}

fied'. The final scores regarding recommendation of the procedure and patient willingness to repeat the procedure were aggregated and dichotomized as positive or negative using the same twothirds cutoff point. Descriptive statistics were calculated including means and standard deviations for the continuous parameters and frequency distributions for the categorical variables. To test the association between the aggregated information scores and patient satisfaction, the $\chi^{2}$ test was used.

\section{Results}

\section{Social Demographics}

Fifty-two $(70.3 \%)$ of the participants were female. At the time of surgery, the mean age was $21.1 \pm 4.1$ years, with $39(52.7 \%)$ patients between 20 and 30 years old, 33 $(44.6 \%)<20$ years old and $2(2.7 \%)>30$ years old. Thirty (40.5\%) and $26(35.1 \%)$ participants came from families with monthly incomes of KWD 500-999 (USD 1,7503,499 ) and KWD 1,000-2,000 (USD 3,500-7,000), respectively. There were $8(10.8 \%)$ participants from families with monthly incomes of either KWD $<500$ or $>2,000$. Two participants chose not to disclose their family's monthly income. A total of $42(56.8 \%)$ patients had a higher education (i.e. a bachelor's, master's or a doctoral degree), 17 (22.9\%) had received a high school diploma and $15(20.3 \%)$ had some high-school education.

\section{Treatment Type and Duration}

The two-jaw procedure (i.e. the maxillary Le Fort I and mandibular bilateral sagittal split osteotomies) was the most commonly performed surgery among the participants in the sample [46 (62.2\%)]. This was followed by the single mandibular procedure in $22(29.7 \%)$ participants and the maxillary procedure in $6(8.1 \%)$. The total treatment duration varied from 3 months to 7 years with a mean of $2.99 \pm 1.61$ years. The mean duration of the postoperative orthodontic treatment was $0.78 \pm 0.76$ years and ranged from 0 months [4 (5.4\%) patients] to 4 years [2 (2.7\%) patients].

\section{Motivation for Treatment}

Thirty-four (45.9\%) patients were self-motivated to undergo surgery, whereas $8(10.8 \%)$ reacted to advice from family, friends or both. The decision was based on a recommendation from an orthodontist for 24 (32.4\%) patients and from a surgeon and a general dentist for 4 (5.4\%).

\section{Patient Information}

The timing and sources of information concerning the surgery and proposed treatment plan were provided to the patients in three phases: before, during and at the end of the presurgical orthodontic treatment. Although the orthodontist was the most prominent source of information before treatment initiation, later this was more evenly distributed between the orthodontist and surgeon. The role of the surgeon as the information provider became more prevalent at the end of presurgical orthodontic treatment; however, the surgeon was rarely the only source of such information.

General Information. The general information is summarized in table 1. Patients reported having been best informed about the significance of patient compliance followed by the notification that orthodontics would be needed before and after surgery. The possibility of surgical, orthodontic or both types of relapse was the information received the least.

Information on Surgical Risks. Four (5.4\%) patients were informed about the possibility of damage to their permanent dentition. In addition, participants were not well informed about the risks associated with the actual surgical procedures, including general anesthesia, bleeding and infection (table 2). Similarly, they were not adequately informed about the surgical risks associ- 
Table 2. Responses to questions regarding the specific information received

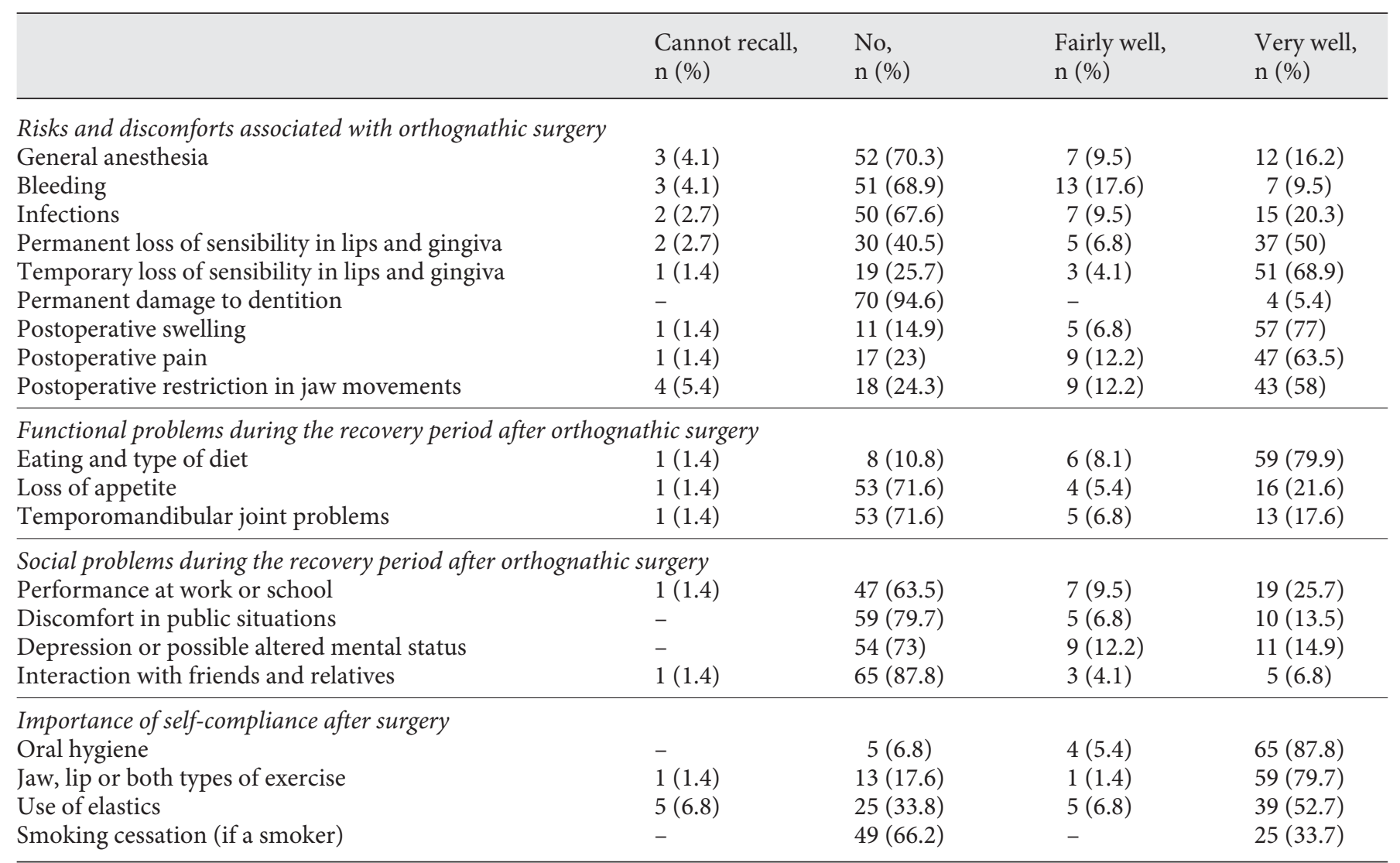

Table 3. Responses to questions concerning patient satisfaction

\begin{tabular}{|c|c|c|c|}
\hline & $\begin{array}{l}\text { Very } \\
\text { satisfied, } \\
\mathrm{n}(\%)\end{array}$ & $\begin{array}{l}\text { Fairly } \\
\text { satisfied, } \\
\mathrm{n}(\%)\end{array}$ & $\begin{array}{l}\text { Not } \\
\text { satisfied, } \\
\mathrm{n}(\%)\end{array}$ \\
\hline Facial appearance & $54(73)$ & $17(23)$ & $3(4.1)$ \\
\hline Jaw joint function & $53(71.6)$ & $18(24.3)$ & $3(4.1)$ \\
\hline Chewing capacity and eating & $59(79.7)$ & $14(18.9)$ & $1(1.4)$ \\
\hline Speech and articulation of sounds & $62(83.8)$ & $11(14.9)$ & $1(1.4)$ \\
\hline Dental appearance & $60(81.1)$ & $7(9.5)$ & $7(9.5)$ \\
\hline Self-confidence level & $64(86.5)$ & $9(12.2)$ & $1(1.4)$ \\
\hline Ability to form relationships & $68(91.9)$ & $6(8.1)$ & - \\
\hline \multicolumn{4}{|l|}{ Overall satisfaction with } \\
\hline orthodontist & $66(89.2)$ & $6(8.1)$ & $2(2.7)$ \\
\hline Overall satisfaction with surgeon & $63(85.1)$ & $9(12.2)$ & $2(2.7)$ \\
\hline
\end{tabular}

ated with the combined orthodontic and orthognathic surgeries.

Information Concerning Possible Functional and Social Problems. Participants reported that the possibility of ex- periencing eating difficulties was well explained to them prior to surgery; however, functional problems such as loss of appetite and temporomandibular joint problems were not well explained (table 2). The least well-informed aspect of preoperative information was with regard to two of the three functional problems, i.e. loss of appetite and temporomandibular joint problems, and all the social problems.

Information Concerning the Need for Compliance. The information in this category on oral hygiene and exercising was reported as being excellent. However, information about the use of elastics and smoking cessation was not as frequently provided.

\section{Patient Satisfaction}

Patient satisfaction with the final treatment result, in terms of function and social effects, is summarized in table 3. Seventy participants (96.4\%) did not regret their decision to undergo combined orthodontic and surgical treatments, and 66 (89.2\%) would recommend the treatment to a friend or family member with similar needs. 
Table 4. Summary of responses to questions concerning overall satisfaction: comparison to previous findings

\begin{tabular}{|c|c|c|c|c|c|c|c|c|c|}
\hline & & $\begin{array}{l}\text { Our } \\
\text { study }\end{array}$ & $\begin{array}{l}\text { Zhou } \\
\text { et al. [6] }\end{array}$ & $\begin{array}{l}\text { Cunningham } \\
\text { et al. [7] }\end{array}$ & $\begin{array}{l}\text { Garvill } \\
\text { et al. [8] }\end{array}$ & $\begin{array}{l}\text { Laufer } \\
\text { et al. [9] }\end{array}$ & $\begin{array}{l}\text { Finlay } \\
\text { et al. [4] }\end{array}$ & $\begin{array}{l}\text { Nurminen } \\
\text { et al. [10] }\end{array}$ & $\begin{array}{l}\text { Rittersma } \\
\text { et al. [5] }\end{array}$ \\
\hline $\begin{array}{l}\text { Do you regret your orthodontic/ } \\
\text { surgical experience? }\end{array}$ & $\begin{array}{l}\text { Yes } \\
\text { No }\end{array}$ & $\begin{array}{r}5.4 \% \\
96.4 \%\end{array}$ & $8 \%$ & - & - & - & $84 \%$ & - & $\begin{array}{r}2.7 \% \\
85.4 \%\end{array}$ \\
\hline $\begin{array}{l}\text { Would you recommend a similar } \\
\text { treatment to others? }\end{array}$ & $\begin{array}{l}\text { Yes } \\
\text { No }\end{array}$ & $\begin{array}{l}89.2 \% \\
10.8 \%\end{array}$ & - & $76.5 \%$ & - & - & $89 \%$ & - & $\begin{array}{r}79.0 \% \\
7.3 \%\end{array}$ \\
\hline
\end{tabular}

Table 5. Responses to questions concerning outcomes relative to pretreatment expectations

\begin{tabular}{lllll}
\hline & $\begin{array}{l}\text { As expected, } \\
\mathrm{n}(\%)\end{array}$ & $\begin{array}{l}\text { Worse than expected, } \\
\mathrm{n}(\%)\end{array}$ & $\begin{array}{l}\text { Better than expected, } \\
\mathrm{n}(\%)\end{array}$ & $\begin{array}{l}\text { Total, } \\
\mathrm{n}(\%)\end{array}$ \\
\hline $\begin{array}{l}\text { Postoperative pain } \\
\text { Postoperative numbness }\end{array}$ & $15(20.3)$ & $18(24.3)$ & $41(55.4)$ & $74(100)$ \\
Postoperative swelling & $21(28.4)$ & $6(8.1)$ & $47(63.5)$ & $74(100)$ \\
Overall satisfaction & $17(23)$ & $5(6.7)$ & $52(70.3)$ & $74(100)$ \\
\hline
\end{tabular}

Table 6. Positive correlations of the type of information provided presurgically and treatment satisfaction postsurgically

\begin{tabular}{lll}
\hline Presurgical information type & Postsurgical treatment satisfaction & p value \\
\hline Surgical risks & Overall satisfaction & 0.040 \\
Surgical risks and postoperative discomfort & Satisfaction with the surgeon & 0.031 \\
Surgical risks and postoperative discomfort & $\begin{array}{l}\text { Increased likelihood that the perceived discomfort was as } \\
\text { expected }\end{array}$ & $\begin{array}{l}\text { Satisfaction with the orthodontist } \\
\text { Phases of orthodontics }\end{array}$ \\
\hline
\end{tabular}

Sixty-two (83.8\%) said they would repeat the same treatment if needed (table 4).

Expectation of Discomfort. Fifty-two (70.3\%) of the participants found the postoperative swelling to be less problematic than they had expected. Forty-seven (63.5\%) also found pain to be less severe than they had expected (table 5).

Associations. Socioeconomic status was negatively associated with patient satisfaction $(\mathrm{p}=0.008)$; patients of higher socioeconomic status were less likely to be satisfied. The positive correlations of the type of information provided presurgically and treatment satisfaction postsurgically are given in table 6 .

\section{Discussion}

The finding of this study that the majority of patients who sought combined orthodontic and surgical treatments were female confirmed that of previous studies [3, $8,10-15]$. A probable explanation could be related to the fact that women are more concerned with appearance [16] than men. The age of participants in this sample at the time of surgery suggests that in Kuwait, few patients $>30$ years of age undergo combined orthodontic and surgical corrections, contrary to previous studies $[1,11,14]$. The age limit of 30 years in this study could indicate that patients $>30$ years of age are discouraged from undergoing necessary orthognathic surgery for malocclusion correction in Kuwait. 
The higher the family income, the higher the chances that orthodontic treatment would be received [17]. The results of this study suggest that most patients who undergo orthognathic treatment in Kuwait are of a middle socioeconomic status. This finding might be related to the fact that such treatment is provided free of charge to $\mathrm{Ku}$ waiti patients at $\mathrm{MoH}$ dental clinics. In this study, socioeconomic status was negatively associated with patient satisfaction $(\mathrm{p}=0.008)$. Patients of high socioeconomic status have the resources to seek multiple medical/dental opinions and have access to the Internet, where only successful cases are published. These resources might yield unrealistic expectations, thereby leading to lower levels of satisfaction. We had a higher proportion of highly educated participants than previous studies. Only $20 \%$ of the participants had less than a high school education; Stirling et al. [13] reported twice this number. Although tertiary education in Kuwait is free and the percentage of the population receiving it is slightly higher than the regional average, the education levels in our study were lower than those in the population reported on by Stirling et al. [13] and two statistical reports [18, 19]. The reason for this finding might be that people with a higher education openly accept undergoing orthognathic surgery in $\mathrm{Ku}$ wait since they can read more about it and know how it can affect their lives positively.

Our findings suggest that the risks of the surgical procedures and the possibility of postoperative problems should be better explained; this was particularly evident with regard to the social aspects. This finding might reflect the fact that the surgeons are typically less involved in patient communication before and during the preoperative orthodontic stages and tend to become more involved at the end of the preoperative orthodontic treatment. These findings suggest that changes in this routine might be advantageous for patients. Regular meetings between the surgeon and orthodontist during the preoperative stage might lead to improved communication among the orthodontist, surgeon and patient.

In our study, only 4 (5.4\%) patients were advised by their general dentist to seek combined orthodontic and surgical treatments. On the other hand, Modig et al. [20] reported that approximately $70 \%$ of the patients were advised by their general dentist to undergo combined orthodontic and surgical treatments for malocclusion correction. The general dentist is the primary caregiver in $\mathrm{Ku}$ wait who refers patients when specialist care is needed. The better the general dentist is educated about major skeletal malocclusions, the better he or she can assume the major role of directing patients to the orthodontist.
Our results showed that many participants were satisfied with their postsurgical results. Table 4 shows varying results across previous studies. Consistent with other research $[8,13]$, our study revealed that increased information concerning discomfort and surgical risks increased the level of patient satisfaction.

No systematic group differences in patient demographics were detected between the 74 consenting patients and the 71 patients who either refused to participate or could not be reached, which ensures that our sample represented the patient pool.

\section{Limitations}

The fact that certain patients underwent surgery a long time ago is a weakness of all retrospective studies. Therefore, possible biases due to the lack of accurate patient memory when conducting the interviews cannot be ruled out. Retrospective studies do not allow satisfaction comparisons before and after surgery; thus, conclusions drawn based on the level of satisfaction measured only after surgery should be treated with caution. Another limitation is related to the fact that the study relied on information from patients with available chart records. Therefore, selection and detection biases due to the lack of documentation regarding unsuccessful patients cannot be ruled out. Prospective studies are encouraged. The material is limited to $\mathrm{MoH}$ clinics because at the time of data collection, only $\mathrm{MoH}$ clinics provided that kind of treatment. The small number of respondents was a representation of how uncommon the treatment was. However, in the last decade, orthognathic surgery has also been carried out at Kuwait University and in private hospitals. New data will become available to conduct similar research on a wider scale. Another limitation would be that none of the respondents reported being unsatisfied after recategorizing the outcome satisfaction response scores.

\section{Conclusions}

In general, patients undergoing orthognathic surgery in Kuwait are satisfied and well informed; however, information concerning surgical risks and functional discomfort can be improved. Participants were more likely to be satisfied when they were provided information concerning discomfort and surgical risks. Our findings might be of significance for the establishment of appropriate protocols for how and when to inform patients who are likely to benefit from combined orthodontic and surgical 
malocclusion corrections. General dentists should be further educated to diagnose major skeletal malocclusions and be able to assume the important role of referring patients to the orthodontist.

\section{Acknowledgements}

We thank Prof. Jon Artun, Dr. Rashed Al-Azmi, Dr. Ashraf Mokhtar, Dr. Emad Al-Nejada, Dr. Petr Schutz and Prof. Mohammad Al-Massri for providing information and assisting us at various stages of this study.

\section{References}

1 Ostler S, Kiyak A: Treatment expectations versus outcomes among orthognathic surgery patients. Int J Adult Orthodon Orthognath Surg 1991;6:247-255.

2 Bailey LJ, Proffit WR, White R Jr: Assessment of patients for orthognathic surgery. Semin Orthod 1999;5:209-222.

3 Olson RE, Laskin DM: Expectations of patients from orthognathic surgery. J Oral Surg 1980;38:283-285.

4 Finlay PM, Atkinson JM, Moos KF: Orthognathic surgery: patient expectations; psychological profile and satisfaction with outcome. Br J Oral Maxillofac Surg 1995;33:9-14.

5 Rittersma J, Casparie AF, Reernik E: Patient information and patient preparation in orthognathic surgery: a medical audit study. J Maxillofac Surg 1980;8:206-209.

-6 Zhou YH, Hägg U, Rabie A: Patient satisfaction following orthognathic surgical correction of skeletal class III malocclusion. Int J Adult Orthodon Orthognath Surg 2001;16: 99-107.

7 Cunningham SJ, Hunt NP, Feinmann C: Perceptions of outcome following orthognathic surgery. Br J Oral Maxillofac Surg 1996;34: 210-213.

8 Garvill J, Garvill H, Kahnberg K, et al: Psychological factors in orthognathic surgery. J Craniomaxillofac Surg 1992;20:28-33.
9 Laufer D, Glick D, Gutman D, et al: Patient motivation and response to surgical correction of prognathism. Oral Surg Oral Med Oral Pathol 1976;41:309-313.

10 Nurminen L, Pietilä T, Vinkka-Puhakka H: Motivation for and satisfaction with orthodontic-surgical treatment: a retrospective study of 28 patients. Eur J Orthod 1999;21: 79-87.

11 Hillerström K, Sörensen S, Wictorin L: Biological and psycho-social factors in patients with malformation of the jaws. II. Twelve months after maxillo-facial surgery. Scand J Plast Reconstr Surg 1971;5:34-40.

12 van Steenbergen E, Litt MD, Nanda R: Presurgical satisfaction with facial appearance in orthognathic patients. Am J Orthod Dentofacial Orthop 1996;109:653-659.

13 Stirling J, Latchford G, Morris DO, et al: Elective orthognathic treatment decision making: a survey of patient reasons and experiences. J Orthod 2007;34:113-127.

14 Kiyak HA, McNeill W, West RA, et al: Predicting psychological responses to orthognathic surgery. J Oral Maxillofac Surg 1982; 40:150-155.

15 Heldt L, Haffke EA, Davis LF: The psychological and social aspects of orthognathic treatment. Am J Orthod 1982;82:318-28.
16 Lazaridou-Terzoudi T, Kiyak HA, Moore R, et al: Long-term assessment of psychological outcomes of orthognathic surgery. J Oral Maxillofac Surg 2003;61:545-552.

17 Proffit WR, Fields HW Jr, Moray LJ: Prevalence of malocclusion and orthodontic treatment need in United States estimates from the NHANES III survey. Int J Adult Orthodon Orthognath Surg 1998;13:97-106.

18 United Nations Educational, Scientific and Cultural Organization: UIS statistics in brief. Education (all levels) profile - UK and Northern Ireland, UNESCO, 2011. http://stats.uis. unesco.org/unesco/TableViewer/document. aspx ? ReportId $=121 \& I F \_L a n g u a g e=e n g \&$ BR_Country $=8260 \&$ BR_Region $=40500$ (accessed October 7, 2013).

19 United Nations Educational, Scientific and Cultural Organization: UIS statistics in brief. Education (all levels) profile - Kuwait, UNESCO, 2011. http://stats.uis.unesco.org/unesco/ TableViewer/document.aspx?ReportId= $121 \&$ IF_Language $=$ eng \& BR_Country $=$ 4140\&BR_Region=40525 (accessed October 7, 2013).

20 Modig M, Andersson L, Wårdh I: Patients' perception of improvement after orthognathic surgery: pilot study. Br J Oral Maxillofac Surg 2006;44:24. 